\title{
Study of Environmental Enteropathy and Malnutrition (SEEM) in Pakistan: protocols for biopsy based biomarker discovery and validation
}

Najeeha T. Iqbal ${ }^{1,2+}$, Sana Syed ${ }^{1,3+}$, Kamran Sadiq ${ }^{1}$, Marium N. Khan ${ }^{3}$, Junaid lqbal ${ }^{1,2}$, Jennie Z. Ma ${ }^{4}$, Fayaz Umrani ${ }^{1}$, Sheraz Ahmed', Elizabeth A. Maier ${ }^{5}$, Lee A. Denson ${ }^{5}$, Yael Haberman $^{5}$, Monica M. McNeal ${ }^{6}$, Kenneth D. R. Setchell' Xueheng Zhao ${ }^{7}$, Shahida Qureshi', Lanlan Shen ${ }^{8}$, Christopher A. Moskaluk' ${ }^{9}$ Ta-Chiang Liu ${ }^{10}$, Omer Yilmaz ${ }^{11,12}$, Donald E. Brown ${ }^{13}$, Michael J. Barratt ${ }^{14}$, Vanderlene L. Kung ${ }^{14}$, Jeffrey I. Gordon ${ }^{14}$, Sean R. Moore ${ }^{3^{*}+}$ and S. Asad $\mathrm{Ali}^{1 *+}$

\begin{abstract}
Background: Environmental Enteropathy (EE), characterized by alterations in intestinal structure, function, and immune activation, is believed to be an important contributor to childhood undernutrition and its associated morbidities, including stunting. Half of all global deaths in children $<5$ years are attributable to under-nutrition, making the study of EE an area of critical priority.

Methods: Community based intervention study, divided into two sub-studies, 1) Longitudinal analyses and 2) Biopsy studies for identification of EE features via omics analyses. Birth cohorts in Matiari, Pakistan established: moderately or severely malnourished (weight for height Z score $(\mathrm{WHZ})<-2)$ children, and well-nourished (WHZ > 0) children. Blood, urine, and fecal samples, for evaluation of potential biomarkers, will be collected at various time points from all participants (longitudinal analyses). Participants will receive appropriate educational and nutritional interventions; non-responders will undergo further evaluation to determine eligibility for further workup, including upper gastrointestinal endoscopy. Histopathological changes in duodenal biopsies will be compared with duodenal biopsies obtained from USA controls who have celiac disease, Crohn's disease, or who were found to have normal histopathology. RNA-Seq will be employed to characterize mucosal gene expression across groups. Duodenal biopsies, luminal aspirates from the duodenum, and fecal samples will be analyzed to define microbial community composition (omic analyses). The relationship between histopathology, mucosal gene expression, and community configuration will be assessed using a variety of bioinformatic tools to gain better understanding of disease pathogenesis and to identify mechanism-based biomarkers. Ethical review committees at all collaborating institutions have approved this study. All results will be made available to the scientific community.
\end{abstract}

(Continued on next page)

* Correspondence: sean.moore@virginia.edu; asad.ali@aku.edu

${ }^{\dagger}$ Najeeha T. lqbal and Sana Syed are Co-first authors

† Sean R. Moore and S. Asad Ali contributed equally to this paper and are

Co-corresponding authors

${ }^{3}$ Department of Pediatrics, University of Virginia, Charlottesville, VA, USA

'Department of Paediatrics and Child Health, Aga Khan University, Karachi,

Pakistan

Full list of author information is available at the end of the article

(c) The Author(s). 2019 Open Access This article is distributed under the terms of the Creative Commons Attribution 4.0 International License (http://creativecommons.org/licenses/by/4.0/), which permits unrestricted use, distribution, and reproduction in any medium, provided you give appropriate credit to the original author(s) and the source, provide a link to the Creative Commons license, and indicate if changes were made. The Creative Commons Public Domain Dedication waiver (http://creativecommons.org/publicdomain/zero/1.0/) applies to the data made available in this article, unless otherwise stated. 


\begin{abstract}
(Continued from previous page)
Discussion: Operational and ethical constraints for safely obtaining intestinal biopsies from children in resource-poor settings have led to a paucity of human tissue-based investigations to understand and reverse EE in vulnerable populations. Furthermore, EE biomarkers have rarely been correlated with gold standard histopathological confirmation. The Study of Environmental Enteropathy and Malnutrition (SEEM) is designed to better understand the pathophysiology, predictors, biomarkers, and potential management strategies of EE to inform strategies to eradicate this debilitating pathology and accelerate progress towards the 2030 Sustainable Development Goals.
\end{abstract}

Trial registration: Retrospectively registered; clinicaltrials.gov ID NCT03588013.

Keywords: Childhood undernutrition, Low- middle income countries, Environmental enteropathy, Gut barrier function, Endoscopy, Duodenal biopsies, Small intestinal microbiota, Mucosal gene expression

\section{Background}

Environmental Enteropathy (EE), an acquired small intestinal condition, is a consequence of the continuous burden of immune stimulation by fecal-oral exposure to enteropathogens leading to a persistent acute phase response and chronic inflammation [1,2]. First described in the 1960s and 1970s [3-5] in studies from Asia, Africa and Central America, morphological changes or functional signs of EE were identified in a high proportion of apparently healthy adults and children [6-9]. EE can be characterized histologically by villus shortening, crypt hyperplasia and resultant decrease in the surface area of mature absorptive intestinal epithelial cells which leads to macro- and micronutrient malabsorption [1, 10]. Concomitant intestinal leakage or permeability can be estimated by dual sugar absorption tests which have been widely used as a surrogate for biopsy based diagnoses $[11,12]$. Permeability can lead to translocation of microbes or microbial products which along with the intestinal inflammatory nidus, can produce systemic immune activation. This chronic inflammation along with malabsorption are postulated to be the mechanisms through which EE contributes to undernutrition, especially linear growth faltering $[13,14]$. Undernutrition is implicated in $45 \%$ of the 5 million annual deaths in children under 5 years of age [15] and linear growth failure (stunting, length-for-age $\mathrm{Z}$ score $<-2$ ) is a common manifestation of undernutrition, afflicting $\sim 155$ million under-fives worldwide [16]. Stunting serves as a clinical marker for lifelong impairments in physical, neurocognitive, vaccine immunological response, and socioeconomic potential [17-20]. Our current understanding of EE is limited, in large part, because the tissue affected, the gastrointestinal tract of malnourished children, has been difficult to obtain in resource limited settings. Further, a comprehensive approach incorporating longitudinal surveillance of affected children to identify the impact of EE from other co-morbid conditions is needed to fully capture risk factors for EE. Therefore, we propose a comprehensive study approach which combines longitudinal surveillance of children from birth until 2 years of age, capturing known and postulated risk factors of EE and applying the most advanced tools for the analysis of the intestinal tissue samples. The Study of Environmental Enteropathy and Malnutrition in Pakistan (SEEM Pakistan), is a follow up to our phase 1 study titled 'Identification of Novel Biomarkers for Environmental Enteropathy in Children Using an Evidence Based Approach' $[14,21-23]$, in which we have studied patterns of malnutrition and prevention in a cohort of children in Matiari, Pakistan and looked at potential biomarkers of EE and at the ethical feasibilities of conducting biopsies in a lowand middle income country (LMIC) setting. Building on our experience from this study and related works [14, 2123], our SEEM Pakistan study is designed to better understand the pathophysiology, predictors, biomarkers, and potential management strategies of EE. This report describes the SEEM Pakistan study design, including the materials that are being collected along with proposed analysis including use of machine learning methods.

\section{Methods}

SEEM Pakistan is a multi-institutional collaboration between the Aga Khan University Hospital (AKUH), Pakistan, University of Virginia (UVa), Cincinnati Children's Hospital Medical Center (CCHMC) and Washington University in St. Louis (WUSTL) in the USA, with funding by the Bill and Melinda Gates Foundation (2016 through 2019). Enrollment has been completed and a cohort of 400 children has been established (350 malnourished children and 50 well-nourished healthy controls).

\section{Objectives}

This study aims to (i) establish a cohort of 350 malnourished and 50 well-nourished children in Matiari, Pakistan aged zero to 6 months; (ii) assemble serum, fecal, and urine samples for assessment as biomarkers of EE; (iii) provide educational and nutritional interventions according to the level of malnutrition of the child; (iv) evaluate the subset of malnourished children who fail to respond to educational and nutritional interventions by upper gastrointestinal (UGI) endoscopy to identify treatable 
causes of malnutrition; (v) use the UGI biopsy specimens obtained for detailed assessment of histopathology, gene expression and immune profiling to better characterize the pathophysiology of EE, validate current candidate biomarkers, and discover novel biomarker candidates. Importantly, this study provides a unique opportunity to examine whether there are identifiable relationships between histologically-diagnosed $\mathrm{EE}$ and the configuration of the proximal small intestinal and fecal microbiota. Moreover, preclinical tests of causality will be performed by transplanting bacterial communities recovered from children with EE into gnotobiotic mice and assessing the degree to which these communities transmit histopathologic, transcriptional, proteomic and immunologic features of the children's gut barrier dysfunction phenotypes. With these goals in mind, SEEM is comprised of two primary sub-studies: 1) Longitudinal analyses of growth in birth cohort members and 2) Correlating 'omic phenotyping with biopsy analysis, including correlating gut microbial community features with features of duodenal mucosal gene expression profile and immune phenotypes. Table 1 further describes these two primary sub-studies, including objectives covered under each study, their hypotheses, and the patient population selected for each objective.

\section{Patient and public involvement}

Our enrollment population consists of children under the age of 2 years. Therefore, not the patients themselves but their parents were indirectly involved in certain aspects of SEEM's study design. Our field study staff has ongoing routine feedback and evaluation with the parents of the patients, and the current design was evolved based upon our and patient/parental experience from our phase 1 EE study [14]. For example, due to a parentreported increase in their child's diarrhea after consumption ready-to-use therapeutic food, we replaced it with a locally made supplement (Acha Mum) in the current study. Furthermore, feedback from the parents is encouraged, and all issues and comments are communicated to the study team during weekly community meetings. We plan to disseminate results to each participant/parent at the Matiari field-site office at the end of the study.

\section{Study settings and participants}

The basic framework for the SEEM Pakistan study is described in Figs. 1 and 2. The Department of Paediatrics and Child Health at AKUH has an established field site at Matiari, Pakistan, which is a rural district about 3 hours drive north of Karachi, Pakistan. We anticipated enrolling 350 children from ages 0 to 6 months with weight for height $\mathrm{Z}$ score $(\mathrm{WHZ})<-2$ at the time of enrollment. We also anticipated enrolling 50 children of the same age with healthy ponderal and linear anthropometric assessments based on consistent $\mathrm{WHZ}>0$ and height for age $\mathrm{Z}$ score $(\mathrm{HAZ})>-1$ on two consecutive visits between 3 to 6 months, to serve as healthy controls. Administration of routine rotavirus vaccine will be facilitated as a part of our study, and other Expanded Program on Immunizations (EPI) vaccines will also be facilitated as part of other ongoing research activities.

Blood, urine, and fecal samples will be collected from all participants between 3 and 6, and at 9 months of age as well as at the time of endoscopy for those who undergo the procedure (Table 2). Lastly, feces will be collected from participants eligible for nutritional intervention at 10 months of age (pre-intervention) and then again at around 14 months of age (post-intervention). Duodenal aspirates will also be collected at the time of endoscopy; a dry aspirate (pre-saline lavage) as well as a wet aspirate (post-saline lavage) will be attempted.

After enrollment, the parents/caregivers of all participants will undergo a series of rehabilitative interventions to improve the child's nutritional status. Those participants who remain moderately or severely malnourished (WHZ $<-2$ or $<-3$, respectively) despite interventions will then be eligible for medical evaluation to assess if $\mathrm{s} /$ he merits further clinical workup of malnutrition, including UGI endoscopy, to identify a secondary cause. Those who qualify for UGI endoscopy will also undergo a biopsy workup as described in Table 3.

Because UGI endoscopies are rarely performed in children under 2 in Pakistan and due to ethical and cultural considerations, it is not possible to obtain duodenal biopsies from national healthy children that could serve as a control in our analysis. This is one of the major limitations of our study and as the results from Campbell et al. [10] support the utility of healthy age-matched children from high-income countries for identifying key gut pathogenic pathways in low-income settings, we are proposing to use age-matched controls from the United States for comparison.

Therefore, we plan to enroll 3 different control groups, all comprising of children under the age of 11 years, with a preference to enroll children under the age of 5 years. Our first control group will comprise of 30 healthy children, who will undergo endoscopy at CCHMC as part of a diagnostic workup for digestive symptoms, but whose biopsies and diagnoses are not supportive of eosinophilic esophagitis, celiac disease, or inflammatory bowel disease, and who were not treated with antibiotics $\leq 4$ weeks prior to endoscopy.

As EE and celiac disease share some shared histopathological features $[24,25]$, we will focus on celiac disease as an enteropathy control group. We plan to enroll 30 children with newly diagnosed celiac disease per endoscopy at CCHMC to assess the extent to which gene 
Table 1 Objectives, hypotheses, and study population of the primary SEEM sub-studies

\begin{tabular}{|c|c|c|c|}
\hline Sub-study & Objectives & Hypotheses & Study population \\
\hline \multirow{3}{*}{$\begin{array}{l}\text { Longitudinal } \\
\text { growth } \\
\text { analyses }\end{array}$} & $\begin{array}{l}\text { Longitudinal growth } \\
\text { analysis with } \\
\text { biomarkers }\end{array}$ & $\begin{array}{l}\text { Blood, urine, \& fecal biomarkers } \\
\text { collected from malnourished \& healthy } \\
\text { participants will show differences \& will } \\
\text { enable us to identify biomarkers which } \\
\text { can serve as predictors of growth. }\end{array}$ & \multirow{2}{*}{$\begin{array}{l}\text { 1) } 350 \text { children aged } 0-6 \\
\text { months with } W H Z<-2 \text { at time } \\
\text { of enrollment } \\
\text { 2) } 50 \text { children with } W H Z>0 \\
\text { and } H A Z>-1 \text { at } 2 \text { consecutive } \\
\text { visits aged } 3-6 \text { months } \\
\text { Once these cohorts are } \\
\text { established, blood, urine, and } \\
\text { stool samples will be collected } \\
\text { from all participants as detailed } \\
\text { in Table } 2 A \text {. Anthropometric } \\
\text { measurements will be recorded } \\
\text { monthly. }\end{array}$} \\
\hline & $\begin{array}{l}\text { Longitudinal growth } \\
\text { analysis with } \\
\text { metabolomics }\end{array}$ & $\begin{array}{l}\text { Targeted \& untargeted metabolites } \\
\text { from blood, urine, \& stool samples from } \\
\text { malnourished \& healthy participants } \\
\text { will be used for metabolomic testing \& } \\
\text { will show metabolomics differences; } \\
\text { will allow identification of metabolomic } \\
\text { signatures which can serve as } \\
\text { predictors of growth. }\end{array}$ & \\
\hline & $\begin{array}{l}\text { Longitudinal growth } \\
\text { analysis with } \\
\text { microbiome }\end{array}$ & $\begin{array}{l}\text { Microbiota/microbiome in malnourished } \\
\& \text { healthy children will show significant } \\
\text { differences. These differences will } \\
\text { highlight the development of the } \\
\text { microbiota/microbiome \& enable } \\
\text { development of metrics to quantify } \\
\text { deviations from normal. }\end{array}$ & $\begin{array}{l}\text { 1) } 350 \text { children aged } 0-6 \\
\text { months with } W H Z<-2 \text { at time } \\
\text { of enrollment } \\
\text { 2) } 50 \text { children with } W H Z>0 \\
\text { and } H A Z>-1 \text { at } 2 \text { consecutive } \\
\text { visits aged } 3-6 \text { months } \\
\text { Once cohorts are established, } \\
\text { microbiota/ microbiome } \\
\text { maturation will be evaluated } \\
\text { from monthly fecal samples. } \\
\text { Microbiota/microbiome } \\
\text { maturation will be correlated to } \\
\text { monthly anthropometric } \\
\text { measurements. }\end{array}$ \\
\hline \multirow{3}{*}{$\begin{array}{l}\text { Correlating } \\
\text { 'omic } \\
\text { phenotyping } \\
\text { with biopsy } \\
\text { analysis }\end{array}$} & $\begin{array}{l}\text { Correlate microbiota/ } \\
\text { microbiome at the } \\
\text { time of biopsy with } \\
\text { biopsy analysis }\end{array}$ & $\begin{array}{l}\text { Microbial community analyses will } \\
\text { differ between groups. Correlation with } \\
\text { biopsy image analysis will enable } \\
\text { identification of biopsy features which } \\
\text { correlate with microbial community } \\
\text { features in each group. }\end{array}$ & \multirow{3}{*}{$\begin{array}{l}\text { 1) Enrolled participants from } \\
\text { Matiari cohort who undergo UGI } \\
\text { endoscopy } \\
\text { 2) CCHMC celiac cohort } \\
\text { 3) CCHMC healthy cohort } \\
\text { 4) CCHMC Crohn's cohort } \\
\text { Microbiome, metabolomics, and } \\
\text { transcriptomic analysis at the } \\
\text { time of biopsy will be correlated } \\
\text { with biopsy image analysis. }\end{array}$} \\
\hline & $\begin{array}{c}\text { Correlate } \\
\text { metabolomics at the } \\
\text { time of biopsy with } \\
\text { biopsy analysis }\end{array}$ & $\begin{array}{l}\text { Metabolomic analyses will differ } \\
\text { between groups. Correlation with } \\
\text { biopsy image analysis will enable } \\
\text { identification of biopsy features which } \\
\text { correlate with metabolomics \& } \\
\text { microbial community features in each } \\
\text { group. }\end{array}$ & \\
\hline & $\begin{array}{c}\text { Correlate } \\
\text { transcriptomics at the } \\
\text { time of biopsy with } \\
\text { biopsy analysis }\end{array}$ & $\begin{array}{l}\text { Transcriptomic analyses will differ } \\
\text { between groups. Correlation with } \\
\text { features present in biopsy images, } \\
\text { metabolite profiles, \& the microbial } \\
\text { community will allow for better disease } \\
\text { severity/mechanism classification. }\end{array}$ & \\
\hline
\end{tabular}

signatures and associated biologic pathways for children with celiac disease or EE overlap or differ. Lastly, while we recognize that duodenal and ileal histopathology in the majority of Crohn's cases differ from celiac disease and EE, the differentially expressed ileal gene signature in Crohn's patients bears remarkable similarities to individual gene expression patterns reported for EE [10, 26], i.e. induction of IFN $_{\gamma}$, REG1B. Therefore, our third control group will be 30 children with newly diagnosed Crohn's disease per endoscopy at CCHMC.

\section{Sample size}

Participants will be recruited from our prospective cohort. Based on our phase 1 cohort [14], we anticipated that the cohort of 50 SEEM patients, with duodenal samples collected by endoscopy, will include at least 20 without a single identified treatable infection, i.e. identified Giardia or H. pylori infection. The primary endpoint guiding our sample size estimate will be the anticipated differences in duodenal IFN $\mathrm{N}_{\gamma}$ and APOA1 gene expression between subjects with EE and healthy controls. We anticipate that induction of IFN $_{\gamma}$ gene expression will be associated with a reduction in APOA1 gene expression as per a recent study on Crohn's disease [27] and that of Bragde et al. on celiac disease [28]. In the Crohn's study, the mean (SD) Reads Per Kilobase per Million Mapped reads (RPKM) $\mathrm{IFN}_{\gamma}$ gene expression at diagnosis was equal to $1.86(2.7)$ in patients with Crohn's, and 0.33(0.38) in healthy controls. The mean (SD) RPKM APOA1 gene expression at diagnosis was 927(1469) in patients with Crohn's, and 3012(3080) in healthy controls. We anticipate similar differences between EE and healthy controls in our study. Based on these results, 30 healthy controls and $25 \mathrm{EE}$ subjects without a specific treatable infection will provide $90 \%$ power to detect such a difference with $\alpha=0.05$. The secondary endpoint will be to perform an undirected analyses to capture the overall gene and signatures that are different between described groups. Based 


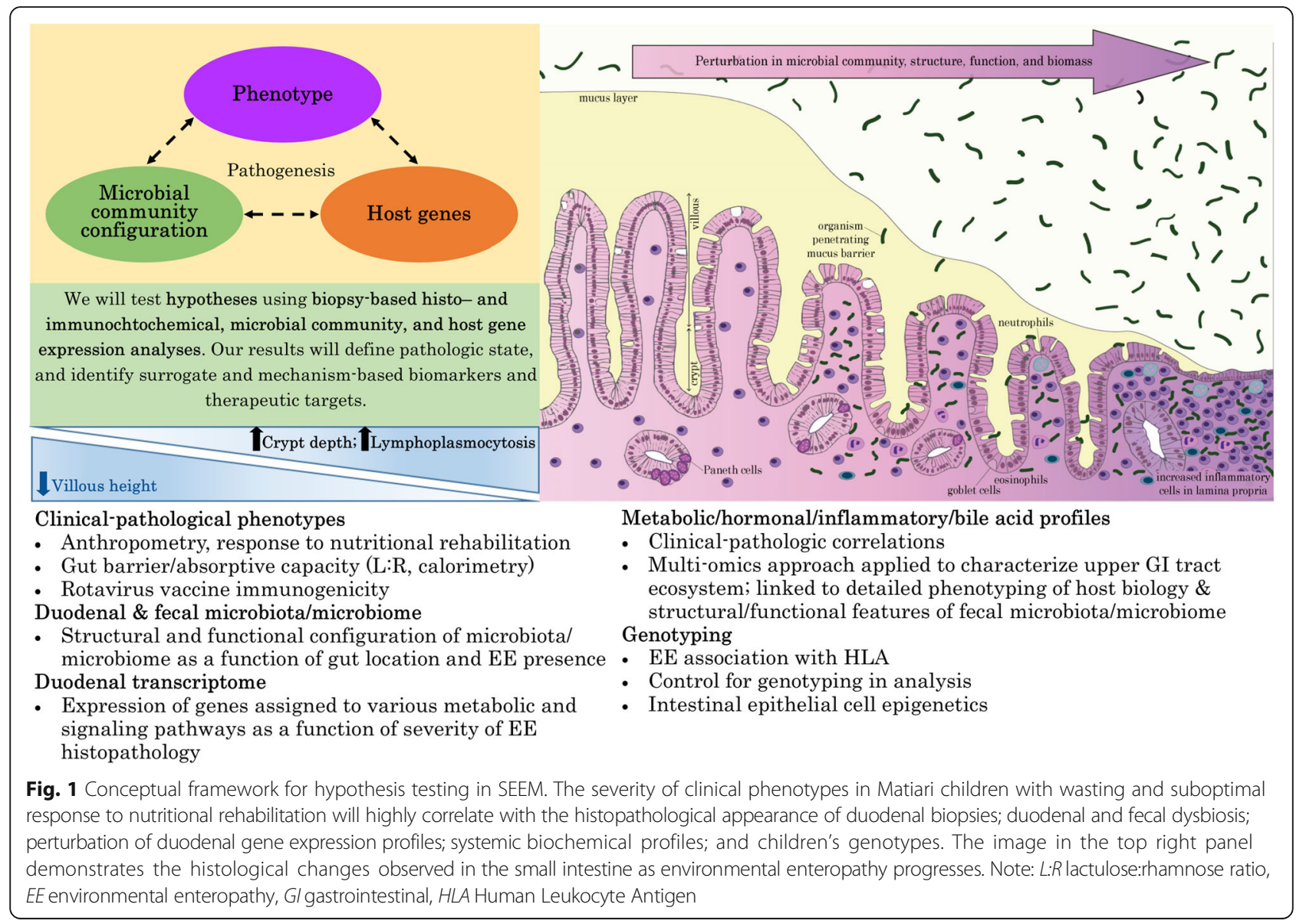

on previously published data for RNA-Seq samples size estimation [29], if we estimate a coefficient of variation of counts of 0.4 as was observed in $90 \%$ of the genes in a range of human studies, alpha of 0.05 and power of 0.8 , a sample size of 20 per group will be needed.

\section{Educational and nutritional interventions, and steps following failure}

Upon enrollment at age $<6$ months, infants will be started in a 4-week home delivered educational program that will focus on breast feeding and complimentary feeding. Counseling will be performed by the study staff using standardized teaching materials. Compliance to the instruction will be recorded during weekly home visits.

If the WHZ remains $<-2$ by 9 months of age despite the initial educational counseling, s/he will be enrolled in the second phase of nutritional and educational intervention. Families will be shown a $10 \mathrm{~min}$ educational video that details the best practices with respect to complimentary feeding best practices on a fortnightly basis, and compliance to the instructions will be recorded during the weekly home visits. If the child remains at $\mathrm{WHZ}<-2$, s/he will undergo the third phase of rehabilitation management according to Pakistan's Community Management of Acute Malnutrition protocol [30]. This will include provision of Acha Mum for the treatment of moderate and severe acute malnutrition to the child at home with close follow up. Utilization of the food supplement will be monitored closely by weekly home visits.

For those children who fail to respond to nutritional rehabilitation and in whom no apparent cause of malnutrition can be identified after basic laboratory workup, we will conduct a more thorough investigation to identify the cause of undernutrition. It is important to note that this nutritional rehabilitation program is immensely supervised, with study staff allowed to visit homes more than once a week to ensure compliance if required. Additionally, our Phase 1 study had a 90.5\% compliance for nutritional intervention, and we will therefore be able to identify which children fail to respond to rehabilitation due to biological reasons vs the unlikely event of failing due to a lack of compliance. If the child remains at $\mathrm{WHZ}<-2$ despite all the above interventions, then s/he will undergo medical evaluation (including a core standardized laboratory panel which includes celiac screening, complete blood count, complete metabolic panel, international normalized ratio, erythrocyte 


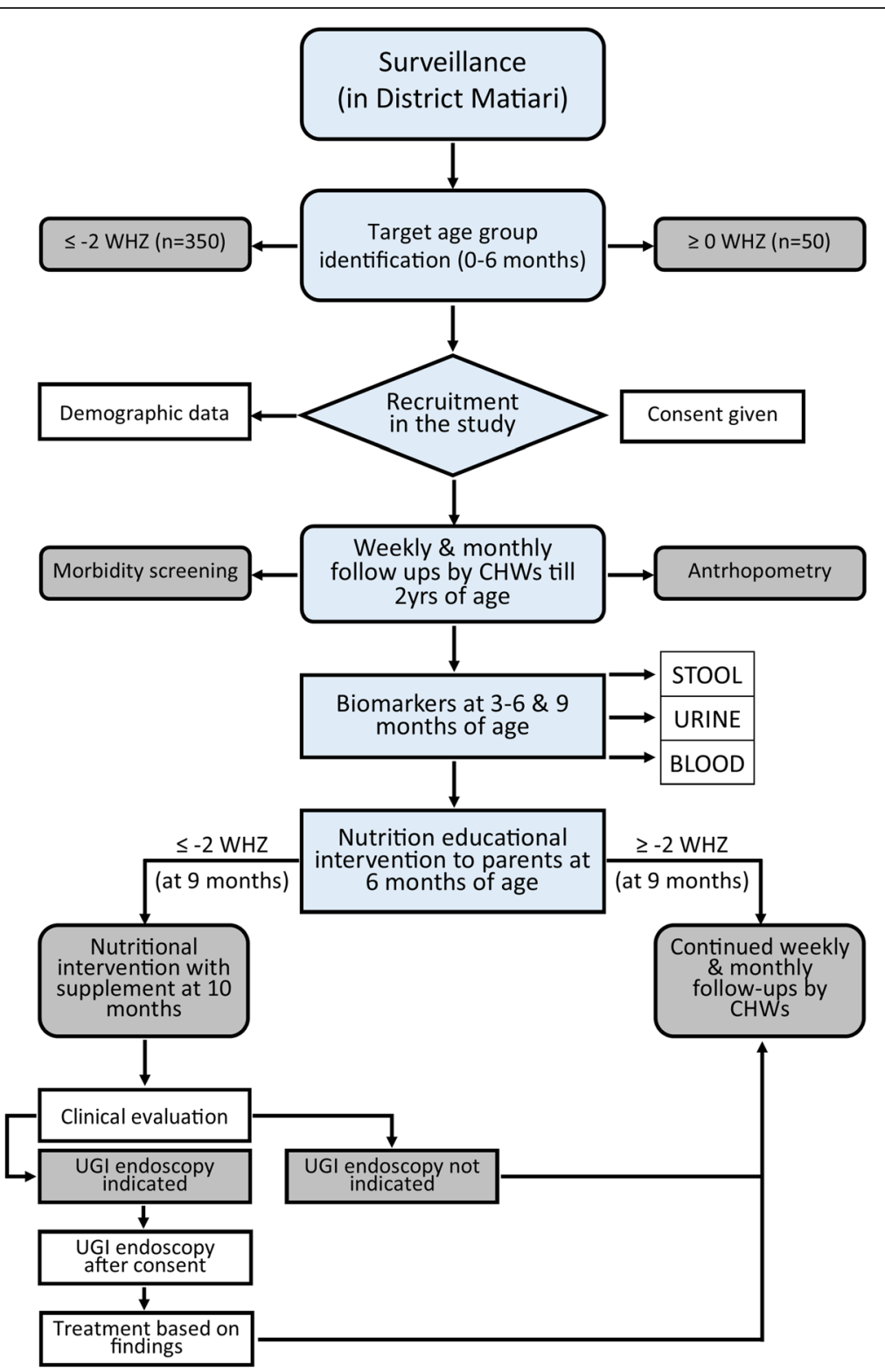

Fig. 2 SEEM Data Collection Process. Note: CHW community health workers, UGl upper Gl, WHZ weight for height Z score

sedimentation rate, and C-reactive protein, additionally, the pediatric gastroenterologist will not be limited to this panel and may order any additional tests as clinically indicated) to assess if there is a clinical indication for further workup to identify a secondary cause of the malnutrition, including UGI endoscopy at AKUH. Diagnostic evaluation, including the UGI endoscopy, will be used to guide further management. For example, dietary management of celiac disease counseling (i.e. initiation of gluten free diet [31]), will be provided to the families of affected children in the local language, and identified infections will be treated according to the standard of care (as was performed in our Phase 1 study for $\mathrm{n}=1$ child diagnosed with celiac disease [14]). Follow-up will be continued to facilitate treatment and ensure the best possible outcomes depending on the pathology identified.

\section{Collection, preparation, storage and transport of biologic samples}

Blood, urine, feces, biopsy tissues, and aspirates will be collected, prepared, preserved, and transported according to the standard operating procedures prepared for this protocol. Samples will be collected at the time points aforementioned.

Community health workers (CHWs) will be responsible for the collection of fecal and urine samples (Additional file 1: Figure S1). Urine samples will be aseptically collected into $100 \mathrm{~mL}$ pediatric urine 
Table 2 Description of sample collection

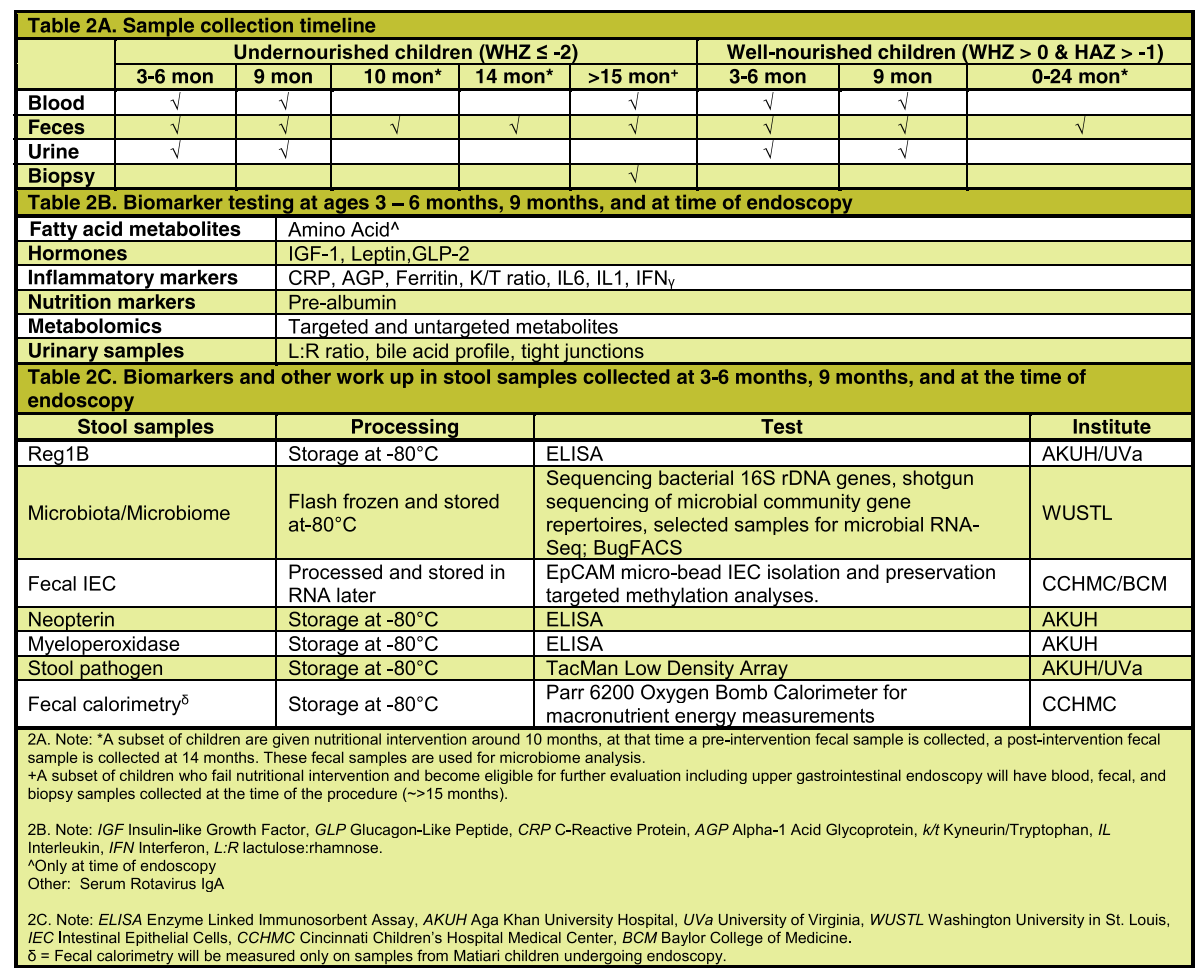

collector bags using a suprapubic tap, $2 \mathrm{~mL}$ of urine will be aliquoted in a $4.5 \mathrm{~mL}$ cryovial and stored at $-2{ }^{\circ} \mathrm{C}$ or $-8^{\circ} \mathrm{C}$ during transport to the Matiari lab and then to the Pediatric Infectious Diseases Research Laboratory (IDRL) at AKUH, once at the IDRL the urine samples will be stored at $-80^{\circ} \mathrm{C}$.

Fecal samples will be collected and cryopreserved within 30 min of production and then transported to the Matiari lab. At the lab, cryovials will be placed into a $-80{ }^{\circ} \mathrm{C}$ freezer prior to shipping on dry ice to Washington University in St. Louis (WUSTL), USA. Approximately $1 \mathrm{~g}$ of fecal material per unique sample/timepoint is required. No additives, preservatives or media will be added to the fecal samples.

For blood samples, trained phlebotomists will collect 3-5 $\mathrm{mL}$ of venous blood in a labeled blood collection tube (neutral vacutainer tube) after following all aseptic precautions. After collection, the labeled tube will be held upright in a test tube rack for $30 \mathrm{~min}$ to allow the blood to clot at room temperature. Each sample will be centrifuged for serum separation and then after successful separation will be pipetted into labeled cryovials. This initial processing will be done at our field site research lab. The vials will be stored in a cooler maintained at 2$8{ }^{\circ} \mathrm{C}$ during transportation to the Pediatric IDRL at AKUH, where they will be stored at $-80^{\circ} \mathrm{C}$ freezers.

Screening for celiac disease will be performed via testing for serum TTG-IgA. We will also screen for the most important determinant of genetic susceptibility for celiac disease i.e. the presence of human leukocyte antigen-DQ (HLA-DQ) heterdimers DQ2 and DQ8 using Genome Wide Association Studies (GWAS). For participants undergoing UGI endoscopy, gastric biopsies (from the antrum and body) will only be obtained at the discretion of the pediatric gastroenterologist performing the endoscopy. These biopsies will be microscopically assessed for Helicobacter pylori associated gastritis on hematoxylin and eosin (H\&E) stain, and a duodenal biopsy will also be microscopically assessed for the presence of Giardia on H\&E stain. The plan for the biopsy workup is detailed in Table 3.

\section{Environmental enteric dysfunction biopsy initiative (EEDBI) consortium and EE score}

The EEDBI Consortium [32] has been assembled from Bill and Melinda Gates Foundation EE biopsy funded projects with cohorts in Zambia [33], Bangladesh [34], and Pakistan. Recently a preliminary EE score, which incorporates acute and chronic inflammation, the presence of inflammatory cells, villus architecture, secretory cells, enterocyte injury, and epithelial detachment, is under development by the consortium, and a preliminary construct was used in our Phase 1 work [22]. The final biopsy scoring system is being developed by a team of pathologists and will be an extension of this preliminary scoring system. We will be using 
Table 3 Plan of biopsy work up on children selected for UGI endoscopy

\begin{tabular}{|c|c|c|c|c|}
\hline Specimen* & Processing & Test & Testing Group & Hypotheses Tested \\
\hline Biopsy 1 & $\begin{array}{l}\text { Paraffin } \\
\text { Embedded }\end{array}$ & $\begin{array}{l}\mathrm{H} \& \mathrm{E} \text { and } \\
\text { Immunofluorescent } \\
\text { staining }\end{array}$ & $\mathrm{AKUH} / \mathrm{CCHMC}$ & Biomarker validation/role of $\mathrm{EE}$ in malnutrition \\
\hline Biopsy 2 & $\begin{array}{l}\text { Paraffin } \\
\text { Embedded }\end{array}$ & $\begin{array}{l}\mathrm{H} \& \mathrm{E} \text { and } \\
\text { Immunofluorescent } \\
\text { staining }\end{array}$ & $\mathrm{AKUH} / \mathrm{CCHMC}$ & Biomarker validation/role of $\mathrm{EE}$ in malnutrition \\
\hline Biopsy 3 & $\begin{array}{l}\text { Paraffin } \\
\text { Embedded }\end{array}$ & $\begin{array}{l}\mathrm{H} \& \mathrm{E} \text { and } \\
\text { Immunofluorescent } \\
\text { staining }\end{array}$ & $\mathrm{AKUH} / \mathrm{CCHMC}$ & Biomarker validation/role of $\mathrm{EE}$ in malnutrition \\
\hline Biopsy 4,5 & RNA later & $\begin{array}{l}\text { Transcriptomics/ } \\
\text { Microbiome }\end{array}$ & $\mathrm{CCHMC/UVa}$ & $\begin{array}{l}\text { Transcriptome/Microbiome: To what extent is the gene expression profile of a } \\
\text { duodenal biopsy portrayed in derived enteroids, and how is this profile related to } \\
\text { histopathologic state and the configuration of the associated } \\
\text { microbiota/microbiome in the donor biopsy. Can changes in enteroid biology be } \\
\text { evoked by exposure to components of the donor's gut microbiota? }\end{array}$ \\
\hline Biopsy 6 & PBS & Enteroids & CCHMC/WUSTL & Minigut development from duodenal tissue \\
\hline $\begin{array}{l}\text { Biopsy } 7 \text { (at } \\
\text { duodenal bulb) }\end{array}$ & $\begin{array}{l}\text { Paraffin } \\
\text { Embedded }\end{array}$ & $\mathrm{H} \& \mathrm{E}$ & $\mathrm{AKUH} / \mathrm{CCHMC}$ & Biomarker validation/role of $\mathrm{EE}$ in malnutrition \\
\hline $\begin{array}{l}\text { Biopsy } 8 \text { (at } \\
\text { duodenal bulb) }\end{array}$ & PBS & Enteroids & AKUH & Minigut development from duodenal tissue \\
\hline $\begin{array}{l}\text { Duodenal Aspirate } \\
(\sim 5-10 \mathrm{ml})\end{array}$ & $\begin{array}{l}\text { Flash Frozen in } \\
\text { aliquots }\end{array}$ & $\begin{array}{l}\text { Microbiota/microbiome } \\
\text { Metabolomics } \\
\text { TaqCard } \\
\text { Total IgA and } \\
\text { Rotavirus IgA }\end{array}$ & $\begin{array}{l}\text { WUSTL/AKUH/ } \\
\text { CCHMC }\end{array}$ & $\begin{array}{l}\text { Validation of K/T ratio as a biomarker from metabolomics. } \\
\text { What is metabolic milieu in which microbes and cells are in? } \\
\text { Enteropathogen load by TaqCard } \\
\text { Bile acid profile: What is the balance of conjugated and deconjugated bile acids in } \\
\text { the upper tract of children with EE? Do higher amounts of deconjugated bile acids } \\
\text { correlate with greater dysbiosis and enteropathy? }\end{array}$ \\
\hline
\end{tabular}

this score on our duodenal biopsies to assess the spectrum of EE.

\section{Biomarkers}

In our Phase 1 work, we noted significant associations between several biomarkers and longitudinal $\mathrm{Z}$ scores for subsequent child height and weight $[17,21,26]$. These biomarkers in addition to an expanded biomarker panel have been selected to test for intestinal barrier structure and function in SEEM. Data will be collected in a longitudinal fashion; monthly anthropometric measurements over 18 months, and biomarker assessment at the aforementioned time points. The biomarkers to be tested in blood and feces are listed in Table 2.

\section{Fecal calorimetry}

In those children who undergo endoscopy at AKUH, fecal calorimetry (6200 Isoperibol Calorimeter; Parr Instrument Company, Moline, IL, USA) will be performed to obtain macronutrient specific determination of fecal energy [35]. Total protein, fat, and carbohydrate energy content of a single fecal aliquot will be compared against the child's clinical phenotype (including severity of wasting), fecal and duodenal enteropathogen burden, endoscopic inflammation, and histologic severity.

\section{Fecal intestinal epithelial cells}

Isolation and characterization of intestinal epithelial cells (IEC) from feces as a "liquid biopsy" for epigeneticbased detection of colorectal cancer has become an area of intense study [36, 37]. We have adapted these emerging technologies to EE, such that the isolation and preservation of exfoliated IECs from fecal specimens (fecal samples taken at 3-6 and 9 months, and additionally from children undergoing UGI endoscopy $48 \mathrm{~h}$ prior to the procedure) is currently in process to allow for assessment of targeted IEC DNA methylation as a function of age, growth, microbiome and enteric illnesses.

\section{Lactose/Rhamnose ( $\mathrm{L}: \mathrm{R})$ test}

The $L: R$ test is a promising functional test that reflects gut permeability and absorptive capacity $[38,39]$. This test is currently being validated in multiple field settings via the EEDBI Consortium [40] and has shown to be more advantageous compared to the lactulose/mannitol test (more often reported dual sugar permeability test in the past two decades) due to lack of pre-dose urinary rhamnose in comparison to mannitol which is used as an inactive ingredient in some oral vaccines and in foods [41]. Dual sugar permeability testing has been used as a surrogate marker of EE [42, 43]. Since our study provides an objective, histology-based diagnosis of $\mathrm{EE}$, we will perform the L:R test in all children (malnourished as well as healthy controls) at approximately 13 months of age. The goal of this is to assess in children who fail to respond to nutritional intervention, whether this failure is associated with an alteration in their intestinal permeability. We will then correlate the findings of the L:R test with the histology of UGI mucosa in malnourished children.

\section{Gut microbiota/microbiome}

Recent work that combines (i) culture-independent analyses of fecal samples collected from healthy members of birth cohorts living in Bangladesh and Malawi with (ii) machine learning algorithms have defined a normal program of gut microbial community development [44-46]. 
This program is manifested by temporal changes in the representation of 'age-discriminatory' bacterial strains. Applying this microbial signature of normal community assembly (maturation) to children diagnosed with severe acute malnutrition (SAM) revealed that their microbiota appear younger than those of their chronologically agematched healthy counterparts living in the same locale $[44,45]$. Moreover, transplantation of microbiota from healthy and undernourished children into young germfree mice has provided preclinical evidence that gut microbiota immaturity is causally related to many of the manifestations of undernutrition [44-46].

To date, studies of the role of the gut microbiota in the pathogenesis of environmental enteropathy (EE) have been limited by challenges in obtaining wellpreserved upper GI communities from individuals whose disease status has been confirmed by endoscopic evaluation. To define the relationship between the configuration of the fecal microbiota and histopathologicallydefined EE in the SEEM cohort, we will first generate Random Forests-derived models of normal gut microbial community development; this will be done using bacterial V4-16S rDNA and shotgun sequencing datasets of community DNA respectively, generated from monthly fecal samples collected for the first 2 years of life from well nourished children (WHZ $>0$ and HAZ > -1) of the Matiari birth cohort. These culture independent methods will be applied to duodenal biopsies and aspirates collected at endoscopy from children who failed to respond to nutritional intervention in order to identify bacterial strains (and members of other domains of life and their viruses) in the proximal small intestine whose representation/abundance are correlated with severity of EE (as assessed by histologic grading [22]). Bacterial strains will be cultured and their genomes sequenced. BugFACS [47] will also be performed on fecal samples obtained from children at the time of endoscopy to identify bacterial strains whose targeting by mucosal IgA is correlated with pathologic features of disease. These results will be further contextualized using data obtained from (i) multi-omics analysis of duodenal specimens from the same children that will be performed at CCHMC and WUSTL (RNA-Seq, metabolomics/proteomics), plus (ii) results of EE biomarker analyses performed on contemporaneously collected plasma and fecal specimens.

A follow-on component of this work will involve transplantation of duodenal microbial community members collected from children with varying degrees of EE severity into germ-free mice fed a prototypic diet consumed by children living in Matiari. The objective will be to test the hypothesis that these communities transmit enteropathy to recipient animals and the relationship between enteropathy features and growth faltering/ undernutrition. These assessments include measurements of (i) lean body mass gain (quantified by whole body magnetic resonance), (ii) bone growth (measured by micro-computed tomography and by serum biomarkers of osteoblastic and osteoclastic activity), (iii) gut barrier function (histochemical and immunohistochemical markers such as EpCAM, claudin-2/-4, tightjunction protein-1, functional assays such as Fluorescein Isothiocyanate (FITC)-labelled dextran permeability, transcriptional (RNA-Seq)/proteomic analyses of different gut segments, and (iv) immune phenotypes (FACS sorting of intestinal and extra-intestinal tissues). If preclinical proof of concept is established for a causal role of the small intestinal microbiota in the pathogenesis of EE, these gnotobiotic models will permit a search for key effector microbes, the mechanisms through which they operate and ultimately tests of therapeutic concepts.

\section{Histopathologic, immunohistochemistry and transcriptomic work up of biopsy specimens}

We hypothesize biopsies from children whose endoscopic workup does not reveal a clear malabsorptive pathology, such as celiac disease, will likely demonstrate advanced features of EE. Previous studies suggest at least two factors contribute to EE: (i) chronic T-cell mediated intestinal damage and (ii) perturbations in microbial community structure/function [13, 48]. Recognizing that our sample will be restricted to children whose wasting $(\mathrm{WHZ} \leq-2)$ is refractory to nutritional intervention, we will comprehensively assess biopsy specimens to better understand the pathology of the proximal small intestinal mucosa in EE.

One such previous attempt utilizing duodenal biopsies compared malnourished children in Gambia with healthy UK age-matched children to better understand the pathogenesis underlying this disorder [10]. This study was, however, restricted to morphometric and targeted immunohistochemical analyses for immune cell markers, and did not investigate gene expression associated with the absorptive epithelial layer more broadly. The authors concluded that cell-mediated Th1 response might impair mechanisms of oral tolerance and drive progressive growth failure despite intensive nutritional intervention [10]. Therefore, we propose to supplement routine clinical histologic morphometric analyses with (i) targeted staining to characterize immune cells and the epithelial layer (working with the UVa Biorepository and Tissue Research Facility (BTRF) we have recently established a protocol for triple color immunohistochemical staining), (ii) RNA-Seq analyses to capture a more inclusive EE gut gene expression signature, (iii) gut biopsy DNA-based $16 \mathrm{~S}$ rDNA characterization of the biopsy-adherent bacterial communities, and (iv) perform 
microbe:gene association studies (Fig. 3). We hope that these data will provide new insights into both disease pathogenesis and treatment, as well as gut-derived circulating biomarkers for disease severity, which may be assayed in future studies using the banked sera from the larger 400 patient SEEM cohort.

Recently, RNA-Seq and 16S rDNA characterization has been employed to characterize the global pattern of ileal gene expression and the ileal microbial community in treatment-naïve pediatric patients with Crohn's disease, disease controls with ulcerative colitis, and healthy control individuals. [27] This was followed by a previously established multivariate approach (MaAsLin) $[49,50]$ to test for associations between selected genes and the microbial taxa. The resultant analyses showed a significant association between expression of components of the APOA1 module and specific Firmicutes and Bacteriodetes [27].

Furthermore, a multivariate analysis which included disease severity and treatment exposures, showed that Crohn's patients with the greatest reduction in APOA1 expression at diagnosis were the least likely to achieve clinical remission with current therapies. This suppression of the anti-oxidant lipoproteins in Crohn's could hence serve as a potential target for future therapies [27].

Similar to the above findings in Crohn's patients, gene expression studies of duodenal biopsies comparing agematched controls and celiac patients likewise demonstrate reduction of APOA1 coupled with induction of IFN $_{\gamma}$ [28]. Together with results described by Campbell et al. [10] showing induction of $\mathrm{IFN}_{\gamma}$ expressing $\mathrm{T}$ cells in children with EE in Gambia, these data suggest that this $\mathrm{IFN}_{\gamma} / \mathrm{APOA} 1$ gene co-expression signature may represent a common pathway of chronic small bowel inflammation and malnutrition.

We plan to test this novel concept by including analysis of duodenal gene expression from disease controls with celiac disease and Crohn's, together with healthy age-matched controls enrolled at CCHMC. This will provide critical insight into shared and unique features of host epithelial and immune pathogenesis, relative to what are likely to be distinct microbial shifts, across these three disorders in undernourished Pakistani and US children. We anticipate that the induction of IFN $_{\gamma}$ in EE will in turn be associated with a reduction in apolipoproteins and enterocyte lipid metabolism pathways similar to Crohn's [27], and celiac disease [28]. Different types of APOA1 interventions are in preclinical development for atherosclerosis and inflammatory bowel disease. If we identify a reduction in APOA1 and associated enterocyte lipid metabolic pathways in EE, such treatment may benefit children with EE as well.

\section{Data analysis plan}

This study will result in a vast dataset containing sociodemographic and anthropometric information, as well as biomarkers found in urine, stool, and blood, and endoscopic biopsy results highlighting histopathologic features of both diseased and healthy gastrointestinal tracts.

The WHO Child Growth Standards (WHO Anthro, Geneva, Switzerland) [51] will be used to calculate zscores, and assess growth both as continuous measures of height-for-age z-score (HAZ), weight-for-age z-score (WAZ) and weight-for-height $\mathrm{z}$-score (WHZ); and as categorized variables of stunting as $\mathrm{HAZ}<-2 \mathrm{SD}$ (standard deviation), underweight as $\mathrm{WAZ}<-2 \mathrm{SD}$ and wasting as $\mathrm{WHZ}<-2 \mathrm{SD}$. Participant descriptive statistics will be presented as means (standard error, SE) and as frequencies (percentages) for continuous and categorical outcomes, respectively. We will also perform simple linear regression for a specific time point and mixed-effects modeling analysis for repeated measurements to study change in growth trends over the follow-up period.

Mass spectrometry will be used to determine serum and urine bile acid profiles and serum non-essential fatty acid levels, and amino acid profiles. In addition, the cellular fraction of the obtained blood will be utilized for DNA extraction and high-throughput genotyping using Infinium HumanOmniExpressExome [52]. Genotyping will also be used to determine HLA typing of the individual and their associated genetic ethnicity. Given the similarities between EE and celiac disease, it will be of interest to determine whether there is also a common HLA genotype associated with EE [53]. Both environmental and genetic factors [54], play roles in gut microbial composition, therefore, we will control for genetic variants (i.e. HLA [55], FUT2 [56]) in some of the planned microbial and gene expression analyses.

We will use a variety of computational/statistical approaches to assess the extent to which expression of various genes and their associated metabolic/signaling pathways in duodenal biopsies in children with celiac disease, Crohn's disease, and EE overlap or differ. We will approach this using several statistical methods; PCA plots; Venn diagrams of the differently expressed genes between celiac disease vs. controls, EE vs. controls, and Crohn's disease vs. controls; and associated pathway analyses. A significant overlap in pathways could provide insights into pathogenesis and new treatment approaches, such as tight junction modulation, which are in development for celiac disease [57]. Gene signatures distinct for EE would further provide a promising source of future therapeutic targets and initial tissue-level validation of promising biomarkers that would be useful for predicting growth and powering studies to test future interventions against EE. We also plan to compare proximal small intestinal duodenal biopsies with distal ileal 


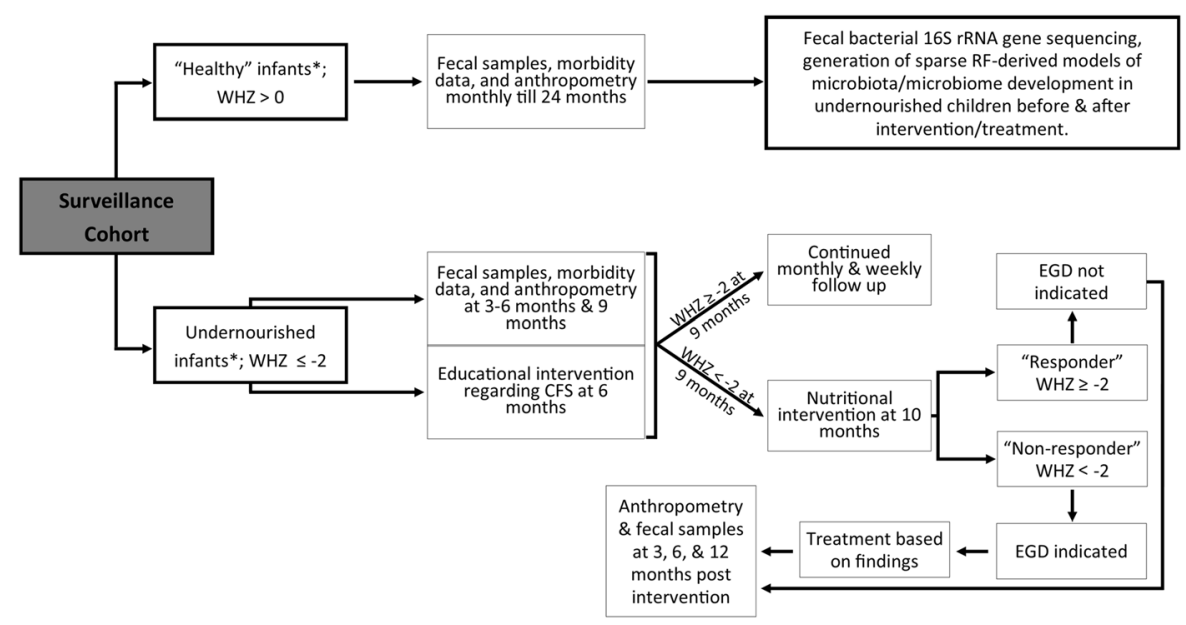

A

Groups, samples, and planned analyses at the time of endoscopy

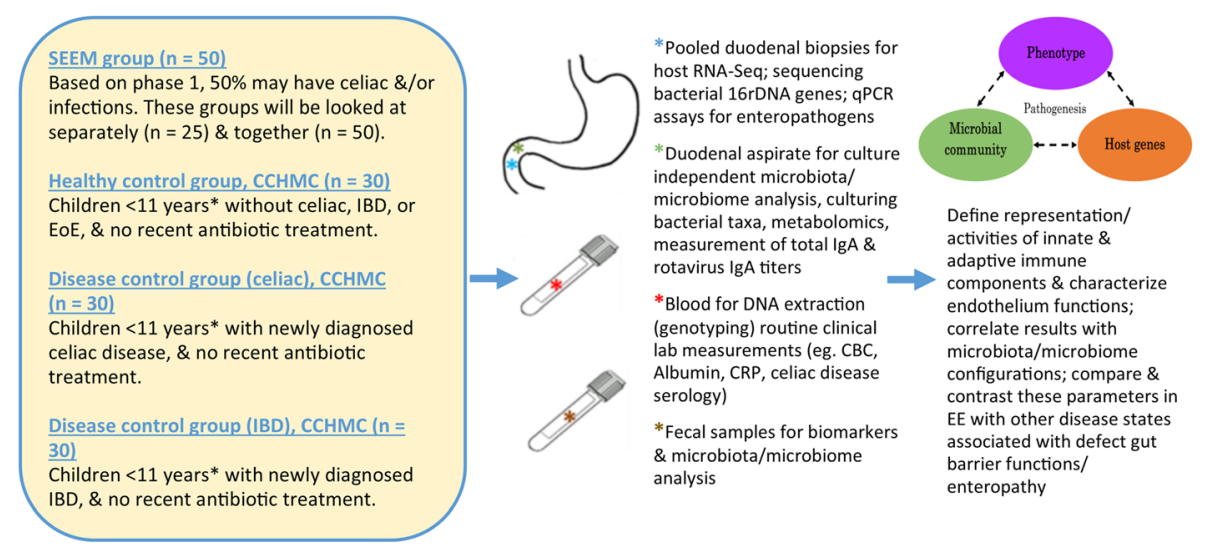

B

Fig. 3 SEEM transcriptome/genetics/biomarkers/microbiome framework at the time of endoscopy. a Is a detailed description of how samples will be collected throughout the study process from the birth cohorts; b Shows the groups, samples, and planned analyses at the time of endoscopy. Note for a: WHZWeight-for-Height Z score, RF Random Forest, EGD Esophagogastroduodenoscopy, infants* $=0-3$ months old. Note for $\mathbf{b}$ : SEEM Study of Environmental Enteropathy and Malnutrition, CCHMC Cincinnati Children's Hospital Medical Center, IBD Inflammatory Bowel Disease, CBC complete blood count, CRPC-Reactive Protein, EE Environmental Enteropathy, ${ }^{*}=$ with a preference to enroll children under 5 years of age

biopsies in the Crohn's cohort to determine how well the duodenal pattern of gene expression reflects the ileum.

Analyses of biopsies from both Crohn's disease and celiac disease patients will also provide us the opportunity to test for the relationship between the microbial community and gene expression signatures. We will test for associations between taxa of the duodenal microbial community and specific clinical and gene expression metadata using Multivariate Analysis by Linear Models (MaAsLin) as has been described in prior studies $[27,49,50]$. A comprehensive description of this analysis method has been published online [58]. In short, for each arcsine square root transformed microbial feature, a model is selected from metadata using gradient boosting (gbm package [59]). Covariates in the selected model are then evaluated controlling for potential confounders using a general linear model. Additionally, confounders will also be assessed via construction of a causal pathway. Multiple comparisons over factor levels will be adjusted using a Bonferroni correction, and multiple hypothesis tests over all clades and metadata will be adjusted with a false discovery rate [60].

All significant $(\alpha<0.05)$ associations will be investigated in the analysis: clinical phenotype (including severity of wasting), stool and duodenal enteropathogen 
burden, endoscopic inflammation, histologic severity, and selected duodenal differentially expressed genes such as IFN $_{\gamma}$ and APOA1. We plan to control for age, gender, and body mass index (as a measure of nutritional status) in our analysis. These analyses will identify specific duodenal microbial taxa associated with differences in $\mathrm{IFN}_{\gamma}$ and/or APOA1 gene expression across the three disorders tested; EE, Crohn's disease, and celiac disease.

Next, analyses of mRNAseq performed on biopsy tissues will be carried out using polyA-RNA selection, fragmentation, cDNA synthesis, adaptor ligation, and library preparation with TRUSeq RNA Sample preparation (Illumina, San Diego, CA, USA). Paired-end 75 bp sequencing will be performed using the Illumina HiSeq 2000 in the CCHMC NIH-supported Digestive Health Center with a minimum depth of 20 million reads per sample. Reads will be aligned using TopHat [61]. The aligned reads will be quantified by Avadis NGS software (Version 1.3.0, Build 163,982 Strand Scientific Intelligence, Inc., San Francisco, CA, USA) using $\mathrm{Hg} 19$ as the reference genome and RPKM as an output. The DESeq algorithm will be used for RPKM normalization within Avadis NGS software. Two more recently applied alternative approaches for quantification will also be assessed using kallisto [62] and eXpress [63].

For RNA-Seq expression and gene enrichment analysis samples will be stratified into specific clinical subgroups including control, EE, celiac disease, and Crohn's disease. For some analyses the EE group will be further sub-divided into those with an identified infection (e.g. Giardia, H. pylori) and those without an identified infectious etiology. In addition, we plan to stratify the Crohn's patient samples by their location to assess expression differences between proximal (duodenal) and distal (ileum) small bowel expression.

Other potential sub-stratification of the EE group will be based on CRP level, histologic severity, response to rotavirus infection (by measuring rotavirus IgA levels), and weight/height outcomes. Differentially expressed genes of the above stratified groups will be determined by the Audic Claverie method using the BenjaminiHochberg false discovery rate correction (FDR 0.05) and analyzed for fold change differences. Normalized intensity values will be used for patterns of gene expression. Pearson correlation based on trend and rate of change will be performed for IFN $_{Y}$ and APOA1 gene expression across defined groups for correlation coefficient of $0.98<|\mathrm{r}|<1$.

ToppGene [64], ToppCluster [65], and IPA (Ingenuity Systems) software will be used to test for functional annotation enrichment analyses of upstream regulators, immune cell types, pathways, phenotype, and biologic functions. Functional annotation enrichment analyses for immune cell type enrichments will be characterized using the Immunological Genome Project data series through ToppGene. Visualization of the functional networks will be obtained using Cytoscape v.3.02 [66].

Lastly, an anticipated challenge in interpreting clinical biopsies from EE and celiac disease will be the possible histopathological overlap between these distinct but related enteropathies [10, 22]. In light of this, we propose to use duodenal biopsy data (converted to whole slide images using Leica SCN400 slide scanner [Meyer Instruments, Houston, TX] and Olympus VS120 Virtual Slide Microscope [Olympus Corporation Inc., Center Valley, Pennsylvania]) from EE, celiac disease and normal healthy biopsy from patients recruited in SEEM and archival duodenal biopsies from the UVa BTRF as data input for a deep learning image analysis algorithm. Deep learning, or machine learning, has been said to be the natural extension to our current statistical analysis [67] especially in the context of multiomic data as in SEEM, and is at the forefront of advances in both technology and medicine [68]. We will use a subtype of deep learning known as Convolutional Neural Networks (CNNs) [69], to detect morphological distinguishing histological features between disease phenotypes. We will also couple our CNN layers with a deconvolution layer [70, 71], and a Gradient Class Activation Map layer [72], which will allow us to trace back high activation features to the corresponding biopsy. This will allow us to enhance the detection of pathologic morphological features that can help distinguish between celiac disease and $\mathrm{EE}$, both when compared to each other and also when compared to healthy duodenal tissue. Furthermore, in addition to applying the EEDBI scoring system, we will use this deep learning driven approach to correlate high activation features to identify multiomic patterns not identified by traditional pathology scoring.

The overall schedule for enrolment, interventions and assessments, including UGI endoscopy and biopsies, is described in Fig. 3; and the data transfer between each collaborating institution is outlined in Fig. 4. To ensure optimal outcomes from this ambitious undertaking, we designed SEEM with monitoring and quality control measures, timelines for milestones, anticipation of challenges, and consideration of ethics and data dissemination.

\section{Safety measures and preparation for adverse events}

One of our major goals was to optimize safety for UGI endoscopies, especially given our LMIC study setting. Although never without elements of risk during the procedure and anesthesia, endoscopy is a very safe procedure when conducted by trained experienced personnel in a well-equipped facility. We have safety data from our own pilot EE phase 1 study in which we successfully performed endoscopy on 11 children with a median (Q1 - 
Q3) age of 22 (20-23) months (14). There is also data from studies conducted in Gambia [10] where children underwent endoscopy under anesthesia, and Zambia [73] where malnourished children underwent endoscopies with collection of duodenal biopsy samples under anesthesia. Neither of these studies reported any endoscopy-related adverse events during or after the procedures.

Additionally, several questions arose in the development and implementation of our Phase 1 EE study and subsequently in SEEM, all of which were reviewed by the Ethical Review Committee (ERC) at AKUH for discussion and resolution. For example, adverse events that may arise during endoscopy were a major concern; to mitigate issues, investigators have developed a priori definitions, assessment criteria and action guidelines including an overnight stay in Karachi prior to return to the subject's village Matiari. Endoscopy of eligible children will be performed at the AKUH (accredited by the Joint Commission International, IL, USA since July 2006 $[74,75])$ where the highest safety standards at par with hospitals in high-income country settings are met including access to a pediatric intensive care unit, pediatric surgeons and dedicated clinical dieticians. Of note, children who fail to respond to nutritional rehabilitation are evaluated by a team of physicians including a trained pediatric gastroenterologist (KS). A qualified anesthetist attends every endoscopy procedure to assess and administer steps as required for sedation. The participant's oxygen saturation level, pulse rate and blood pressure are continuously monitored throughout the procedure. Resuscitation measures and complete pediatric Intensive Care Unit (ICU) support remain available during the procedure for immediate resuscitation if necessary. Clinical findings from the biopsies (e.g. presence of gastritis, $\mathrm{H}$ pylori infection, Giardiasis or diagnosis of celiac disease) are made available as soon as possible so that appropriate treatment can be undertaken. Additionally, morbidity and poor appetite also represent a big challenge; by providing close follow-up, proper counseling and by practicing supportive feeding techniques, this issue can be resolved. Our field team in Matiari is led by two physicians registered by the Pakistan Medical and Dental Council (PMDC), who will oversee these challenges, along with access to a panel of North American trained pediatric subspecialists (SAA - pediatric infectious disease; KS, SS, and SRM - pediatric gastroenterology) for additional expertise as needed.

Other expected adverse events for this protocol are those related to the endoscopy/biopsy procedure that do not qualify as a serious adverse event (SAE) and those associated with phlebotomy and ingestion of lactulose/ rhamnose solution. Both serious and non-SAEs are assessed for their severity, their relationship to study participation and the actions taken and their outcomes. All
SAEs are being reported to the AKUH ERC within $24 \mathrm{~h}$ of the site's awareness of the event. In the event that medical care is required outside of the protocol, all necessary and available treatments are provided, free of cost.

\section{Monitoring and quality control}

With regards to monitoring and quality control, we took several measures to ensure best practices for identifying mislabeling of data. Sample mislabeling has been known to occur, for example mislabeling gender. Such mislabeling was identified when we found that the inferred gender based on genotype did not correlate with actual gender reported on clinical metadata. In light of this samples were rechecked and re-labeled correctly by our study team. A quality control algorithm was developed that combines base calling from the biopsy mRNAseq data and tests its genetic concordance with genotyping of the DNA extracted from the blood [76]. In order to automate this mislabeling, it will be important to apply a similar quality control approach in our study, where incorrect linkage of duodenal expression data to clinical data could result in significant variation in the results. This work will be supported by the same infrastructure at CCHMC currently being used for multi-center inflammatory bowel disease cohort studies. This includes Gene and Protein Expression and Bioinformatics cores of the National Institute of Health (NIH) - supported by CCHMC Digestive Health Center.

\section{Ethical clearance}

The SEEM study protocol has been approved by the AKUH ERC (Protocol 3836-Ped-ERC-15), which is an independent regulatory authority equivalent to Institutional Review Board (IRB). SEEM has also previously received ethical approval from the Cincinnati Children's Hospital Medical Center (CCHMC, Study ID 20160387), and met ethical standards during an audit conducted by the Aga Khan University for an ethical compliance review (Study ID 2446). Collection of specimens for studies on the gut microbiome was approved by the Washington University Human Research Protection Office (IRB ID 201111065). The University of Virginia Institutional Review Board has also approved SEEM (UVa-IRB, Study ID 19856) for the purpose of intestinal tissue triple color immunohistochemistry via the UVa BTRF.

All medical and research ethics will be followed during the interaction with each participant enrolled in SEEM, and also for any and all data collected from them. After complete disclosure, a signed informed consent (Additional file 2) will be obtained from each participant's parent or legal guardian. The consent will be obtained, preferably, where the participant resides. If the parent(s)/ guardian agree to participate in the study, the consent 


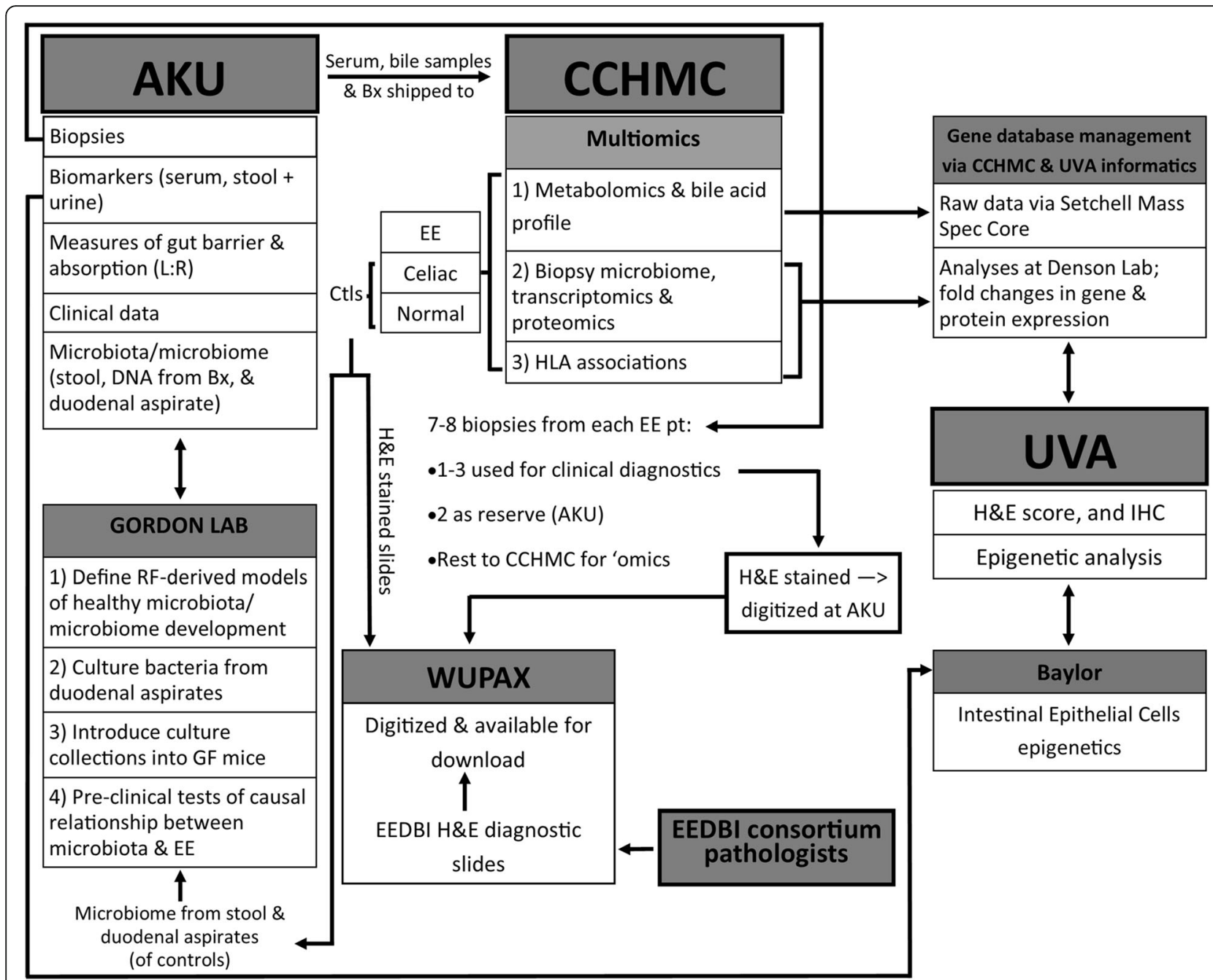

Fig. 4 Framework of data flow in SEEM. Description of how data will be transferred between institutions and a summary of the samples/analyses conducted at each institute. Note: AKU Aga Khan University, L:R Lactulose:Rhamnose ratio, Bx biopsy, EE Environmental enteropathy, CCHMC Cincinnati Children's Hospital Medical Center, HLA Human Leukocyte Antigen, UVA University of Virginia, 'omics multiomics, H\&E Haemotoxylin and Eosin, IHC Immunohistochemistry, EEDBI Environmental Enteric Dysfunction Biopsy Initiative, WUPAXWashington University Digital Pathology Exchange, GF Germ Free

form must be signed or an impression of their thumb must be provided. The investigator and a witness will also sign the form. For endoscopy, a separate consent form is used and the same procedure is followed. The consent form for endoscopy will clearly and fully describe all aspects of the process, including the risks related with the procedure. No information is remained withheld from the participant.

\section{Discussion}

Given the operational and ethical limitations for safely obtaining intestinal biopsies from children in resource-poor settings, there have been few detailed investigations of human tissue in this vulnerable group for whom reversal of EE would be extremely beneficial [14, 17-21]. Furthermore, EE biomarkers studied in different settings have not been correlated with the gold standard of histopathology [17, $18,21]$. SEEM is designed to better understand the pathophysiology, predictors, biomarkers, and potential management strategies of EE to inform strategies to eradicate this debilitating pathology. SEEM will help define EE, however this definition will potentially be biased by the presumption of $\mathrm{EE}$ in children in whom we do not identify an acute or chronic gut infection or other GI pathology. Hence, it will be important to compare our results with those of other biopsy-based EE studies currently underway (which have used different enrolment criteria, but equivalent histopathological assessment and scoring) and to provide an improved or 
modified definition of EE that captures the full spectrum of the disease.

The data, results and other findings resulting from this study will be published only after approval by a committee consisting of the investigators of the protocol. The International Committee of Medical Journal Editors guidelines will be used to establish authorship on papers [77]. As of September 2018, participant enrollment has been completed.

\section{Additional files}

Additional file 1: Figure S1. Urine and fecal sample collection protocol. Panel A describes the urine collection protocol followed by the community health workers (CHWs), and Panel B describes the fecal collection protocol followed by the CHWs for instant transport of fecal samples in a dry shipper for long term storage and preservation for microbiome analysis. Please note: L:R Lactose Rhamnose ratio, $m L$ milliliter, CHW Community Health Worker, AKU Aga Khan University, IDRL Infectious Diseases Research Laboratory.

Additional file 2: Informed consent forms for recruitment of healthy and malnourished children.

\section{Abbreviations}

AKUH: Aga Khan University Hospital; BTRF: Biorepository and Tissue Research Facility; CCHMC: Cincinnati Children's Hospital Medical Center;

CHWs: Community health workers; CNNs: Convolutional Neural Networks; EE: Environmental Enteropathy; EEDBI: Environmental Enteric Dysfunction Biopsy Initiative; EPI: Expanded program on immunization; ERC: Ethical Review Committee; FITC: Fluorescein Isothiocyanate; H\&E: Hematoxylin and eosin; HAZ: Height for age Z score; ICU: Intensive care unit; IDRL: Infectious Diseases Research Laboratory; IEC: Intestinal epithelial cells; IRB: Institutional Review Board; L:R: Lactose:rhamnose; LMIC: Low- and middle income country; MaAsLin: Multivariate Analysis by Linear Models; NIH: National Institute of Health; PMDC: Pakistan Medical and Dental Council; RPKM: Reads per kilobase per million mapped reads; SAE: Serious adverse event; SAM: Severe acute malnutrition; SEEM: Study of Environmental Enteropathy and Malnutrition; UGl: Upper gastrointestinal; UVa: University of Virginia; WHO: World Health Organization; WHZ: Weight for height Z score; WUSTL: Washington University in St. Louis

\section{Acknowledgements}

The authors would like to thank the field workers (community health workers, led by Sadaf Jakro and coordinated by Tauseef Akhund), data management unit (Najeeb Rahman), and laboratory staff (Aneeta Hotwani) at the Aga Khan University for their dedicated work towards this project. We would also like to thank the children and families who participated in this study, and the community leaders and elders of the Matiari society who assisted in recruitment. This study is one of the three major Bill \& Melinda Gates Foundation-supported biopsy-based studies evaluating EE. These studies are coordinated by the Environmental Enteric Dysfunction Biopsy Initiative Consortium (supervised by Drs. Phillip I Tarr, Donna Denno, and Peter Sullivan). We would like to acknowledge Dr. Donna Denno of the University of Washington in Seattle, Dr. Phillip I Tarr of the Washington University in St Louis School of Medicine, and Dr. James P Nataro of the University of Virginia for their valuable insights. Additionally, we would also like to acknowledge Rijah Chhapra of Aga Khan University (medical student class of 2018) for her contribution towards creating the small intestine histological image in Fig. 1.

\section{Authors' contributions}

AA \& SRM equally contributed to the conception and design of the study; AA, SRM, NTI and SS acquired funding for the study; NTI, SS, KS, JI, FU, SA, SQ contributed to the acquisition of the data; NTI, SS, MNK, JZM, EAM, LAD, YH, MMM, KDRS, XZ, LS, CM, TL, OY, DEB, MJB, VLK, JIG contributed to the interpretation and analysis of the data; SRM, AA, NTI, SS, and MNK contributed to drafting the manuscript; all authors critically revised the manuscript for important intellectual content; all authors gave their final approval prior to submission. All authors agree to be accountable for all aspects of the work and certify that this is their own work.

\section{Funding}

This work was supported by the Bill and Melinda Gates Foundation (AA: OPP1138727, SRM: OPP1144149 U19 Al116491 t, JG: OPP1136751), the National Institutes of Health (NTI: TW010697-01), and the University of Virginia Engineering in Medicine Seed grant (SS, DEB). The funders had no role in the design, data collection, analysis of the study, nor the decision to publish or the preparation of this manuscript.

\section{Availability of data and materials \\ Not applicable.}

\section{Ethics approval and consent to participate}

Ethical approval was obtained from the Aga Khan University Hospital Ethical Review Committee (3836-Ped-ERC-15), Cincinnati Children's Hospital Medical Center (CCHMC, Study ID 2016-0387), Washington University in St Louis Human Research Protection Office (IRB ID 201111065), and the University of Virginia Institutional Review Board (UVa-IRB, Study ID 19856). All participants will only be enrolled after they have signed an informed consent. After complete disclosure, a signed informed consent will be obtained from each participant's parent or legal guardian. The consent will be obtained, preferably, where the participant resides. If the parent(s)/guardian agree to participate in the study, the consent form must be signed or an impression of their thumb must be provided. The investigator and a witness will also sign the form. For endoscopy, a separate consent form is used and the same procedure is followed. The consent form for endoscopy will clearly and fully describe all aspects of the process, including the risks related with the procedure.

\section{Consent for publication}

Not applicable.

\section{Competing interests}

The authors declare that they have no competing interests.

\section{Author details}

'Department of Paediatrics and Child Health, Aga Khan University, Karachi, Pakistan. ${ }^{2}$ Department of Biological and Biomedical Sciences, Aga Khan University, Karachi, Pakistan. ${ }^{3}$ Department of Pediatrics, University of Virginia, Charlottesville, VA, USA. ${ }^{4}$ Department of Public Health Sciences, University of Virginia, Charlottesville, VA, USA. ${ }^{5}$ Division of Pediatric Gastroenterology, Hepatology, and Nutrition, Cincinnati Children's Hospital Medical Center, Cincinnati, OH, USA. 'Division of Infectious Diseases, Cincinnati Children's Hospital Medical Center, Cincinnati, OH, USA. ${ }^{7}$ Clinical Mass Spectrometry, Division of Pathology and Laboratory Medicine, Cincinnati Children's Hospital Medical Center, Cincinnati, OH, USA. ${ }^{8}$ Department of Pediatrics, Baylor College of Medicine, USDA/ARS Children's Nutrition Research Center, Houston, TX, USA. 'Department of Pathology, University of Virginia, Charlottesville, VA, USA. ${ }^{10}$ Department of Pathology and Immunology, Washington University School of Medicine, St. Louis, MO, USA. " ${ }^{1}$ Department of Pathology, Massachusetts General Hospital and Harvard Medical School, Boston, MA, USA. ${ }^{12}$ Koch Institute for Integrative Cancer Research at MIT and Department of Biology, Massachusetts Institute of Technology, Cambridge, MA, USA. ${ }^{13}$ Data Science Institute, University of Virginia, Charlottesville, VA, USA. ${ }^{14}$ Center for Genome Sciences and Systems Biology, Washington University School of Medicine, St. Louis, MO, USA.

Received: 2 October 2018 Accepted: 31 May 2019

Published online: 22 July 2019

\section{References}

1. Campbell DI, Elia M, Lunn PG. Growth faltering in rural Gambian infants is associated with impaired small intestinal barrier function, leading to endotoxemia and systemic inflammation. J Nutr. 2003;133(5):1332-8.

2. Solomons NW. Environmental contamination and chronic inflammation influence human growth potential. J Nutr. 2003;133(5):1237.

3. Chacko CJ, Paulson KA, Mathan VI, Baker SJ. The villus architecture of the small intestine in the tropics: a necropsy study. J Pathol. 1969;98(2):146-51.

4. Keusch GT. Subclinical malabsorption in Thailand. I. Intestinal absorption in Thai children. Am J Clin Nutr. 1972;25(10):1062-6. 
5. Lindenbaum J, Gerson CD, Kent TH. Recovery of small-intestinal structure and function after residence in the tropics. I. Studies in peace corps volunteers. Ann Intern Med. 1971;74(2):218-22.

6. Fagundes Neto U, Martins MC, Lima FL, Patricio FR, Toledo MR. Asymptomatic environmental enteropathy among slum-dwelling infants. J Am Coll Nutr. 1994;13(1):51-6.

7. Galpin L, Manary MJ, Fleming K, Ou CN, Ashorn P, Shulman RJ. Effect of Lactobacillus GG on intestinal integrity in Malawian children at risk of tropical enteropathy. Am J Clin Nutr. 2005;82(5):1040-5.

8. Goto R, Panter-Brick C, Northrop-Clewes CA, Manahdhar R, Tuladhar NR. Poor intestinal permeability in mildly stunted Nepali children: associations with weaning practices and Giardia lamblia infection. Br J Nutr. 2002;88(2):141-9.

9. Thurnham DI, Northrop-Clewes CA, McCullough FS, Das BS, Lunn PG. Innate immunity, gut integrity, and vitamin a in Gambian and Indian infants. J Infect Dis. 2000;182(Suppl 1):S23-8.

10. Campbell DI, Murch SH, Elia M, Sullivan PB, Sanyang MS, Jobarteh B, et al. Chronic T cell-mediated enteropathy in rural west African children: relationship with nutritional status and small bowel function. Pediatr Res. 2003;54(3):306-11.

11. Campbell DI, McPhail G, Lunn PG, Elia M, Jeffries DJ. Intestinal inflammation measured by fecal neopterin in Gambian children with enteropathy: association with growth failure, Giardia lamblia, and intestinal permeability. J Pediatr Gastroenterol Nutr. 2004;39(2):153-7.

12. Trehan I, Shulman RJ, Ou CN, Maleta K, Manary MJ. A randomized, doubleblind, placebo-controlled trial of rifaximin, a nonabsorbable antibiotic, in the treatment of tropical enteropathy. Am J Gastroenterol. 2009;104(9):2326-33.

13. Syed S, Ali A, Duggan C. Environmental enteric dysfunction in children. J Pediatr Gastroenterol Nutr. 2016;63(1):6-14.

14. Syed S, Yeruva S, Herrmann J, Sailer A, Sadiq K, Iqbal N, Kabir F, Ahmed K, Qureshi S, Moore SR, Turner J, Ali SA. Environmental Enteropathy in Undernourished Pakistani Children: Clinical and Histomorphometric Analyses. Am J Trop Med Hyg 2018;98(6):1577-1584. doi: https://doi.org/10. 4269/ajtmh.17-0306. Epub 2018 Apr 2. PubMed PMID: 29611507; PubMed Central PMCID: PMC6086170.

15. WHO. Children: reducing mortality 2017 Updated October 2017. Available from: http://www.who.int/mediacentre/factsheets/fs178/en/.

16. Levels and trends in child malnutrition; key findings of the joint malnutrition estimates 2017 edition [internet]. 2017 Available from: https:// www.who.int/en/news-room/fact-sheets/detail/children-reducing-mortality. Cited 04/09/201.

17. Arndt MB, Richardson BA, Ahmed T, Mahfuz M, Haque R, John-Stewart GC, et al. Fecal markers of environmental enteropathy and subsequent growth in Bangladeshi children. Am J Trop Med Hyg. 2016;95(3):694-701.

18. Guerrant RL, Leite AM, Pinkerton R, Medeiros PH, Cavalcante PA, DeBoer M, et al. Biomarkers of environmental enteropathy, inflammation, stunting, and impaired growth in children in Northeast Brazil. PLoS One. 2016;11(9):e0158772.

19. Korpe PS, Petri WA Jr. Environmental enteropathy: critical implications of a poorly understood condition. Trends Mol Med. 2012;18(6):328-36.

20. Naylor C, Lu M, Haque R, Mondal D, Buonomo E, Nayak U, et al. Environmental enteropathy, Oral vaccine failure and growth faltering in infants in Bangladesh. EBioMedicine. 2015;2(11):1759-66.

21. Iqbal NT, Sadiq K, Syed S, Akhund T, Umrani F, Ahmed S, Yakoob MY, Rahman N, Qureshi S, Xin W, Ma JZ, Hughes M, Ali SA. Promising Biomarkers of Environmental Enteric Dysfunction: A Prospective Cohort study in Pakistani Children. Sci Rep 2018;8(1):2966. https://doi.org/10.1038/s41598-018-21319-8. PubMed PMID: $29445110 ;$ PubMed Central PMCID: PMC5813024.

22. Syed S, Dinallo V, Iqbal NT, Di lorio L, Di Fusco D, Guleria S, et al. High SMAD7 and p-SMAD2,3 expression is associated with environmental enteropathy in children. PLoS Negl Trop Dis. 2018;12(2):e0006224.

23. Syed S, lqbal NT, Sadiq K, Ma JZ, Akhund T, Xin W, et al. Serum anti-flagellin and anti-lipopolysaccharide immunoglobulins as predictors of linear growth faltering in Pakistani infants at risk for environmental enteric dysfunction. PLoS One. 2018;13(3):e0193768.

24. Sullivan PB, Marsh MN, Mirakian R, Hill SM, Milla PJ, Neale G. Chronic diarrhea and malnutrition--histology of the small intestinal lesion. J Pediatr Gastroenterol Nutr. 1991;12(2):195-203.

25. Ramakrishna BS, Venkataraman S, Mukhopadhya A. Tropical malabsorption. Postgrad Med J. 2006:82(974):779-87.

26. Peterson KM, Buss J, Easley R, Yang Z, Korpe PS, Niu F, et al. REG1B as a predictor of childhood stunting in Bangladesh and Peru. Am J Clin Nutr. 2013;97(5):1129-33.
27. Haberman Y, Tickle TL, Dexheimer PJ, Kim MO, Tang D, Karns R, et al. Pediatric Crohn disease patients exhibit specific ileal transcriptome and microbiome signature. J Clin Invest. 2014;124(8):3617-33.

28. Bragde $H$, Jansson U, Jarlsfelt I, Soderman J. Gene expression profiling of duodenal biopsies discriminates celiac disease mucosa from normal mucosa. Pediatr Res. 2011;69(6):530-7.

29. Hart SN, Therneau TM, Zhang Y, Poland GA, Kocher JP. Calculating sample size estimates for RNA sequencing data. J Comput Biol. 2013;20(12):970-8.

30. Unicef. National guidelines for the management of acute malnutrition among children under five and pregnant and lactating women:community based management of acute malnutrition (CMAM). Available from: https://www. unicef.org/videoaudio/PDFs/national_guidelines_on_CMAM_Pakistan.pdf.

31. Hill ID, Fasano A, Guandalini S, Hoffenberg E, Levy J, Reilly N, et al. NASPGHAN clinical report on the diagnosis and treatment of gluten-related disorders. J Pediatr Gastroenterol Nutr. 2016:63(1):156-65.

32. Wit JM, Himes JH, van Buuren S, Denno DM, Suchdev PS. Practical application of linear growth measurements in clinical research in low- and middle-income countries. Horm Res Paediatr. 2017;88(1):79-90.

33. Bill and Melinda Gates Foundation. Environmental enteropathy in Zambia: biomarkers defined by pathogenesis 2012 Available from: https://gcgh. grandchallenges.org/grant/environmental-enteropathy-zambia-biomarkersdefined-pathogenesis

34. Mahfuz M, Das S, Mazumder RN, Masudur Rahman M, Haque R, Bhuiyan MMR, et al. Bangladesh environmental enteric dysfunction (BEED) study: protocol for a community-based intervention study to validate non-invasive biomarkers of environmental enteric dysfunction. BMJ Open. 2017;7(8):e017768.

35. Wierdsma NJ, Peters JH, Peters JH, van Bokhorst-de van der Schueren MA, Mulder CJ, Metgod I, van Bodegraven AA. Bomb calorimetry, the gold standard for assessment of intestinal absorption capacity: normative values in healthy ambulant adults. J Hum Nutr Diet. 2014;27(Suppl 2):57-64.

36. Imperiale TF, Ransohoff DF, Itzkowitz SH, Levin TR, Lavin P, Lidgard GP, et al. Multitarget stool DNA testing for colorectal-cancer screening. N Engl J Med. 2014;370(14):1287-97.

37. Yu DH, Gadkari M, Zhou Q, Yu S, Gao N, Guan Y, et al. Postnatal epigenetic regulation of intestinal stem cells requires DNA methylation and is guided by the microbiome. Genome Biol. 2015;16:211.

38. van Nieuwenhoven MA, Geerling BJ, Deutz NE, Brouns F, Brummer RJ. The sensitivity of the lactulose/rhamnose gut permeability test. Eur J Clin Investig. 1999;29(2):160-5.

39. van Wijck K, Verlinden TJ, van Eijk HM, Dekker J, Buurman WA, Dejong CH, et al. Novel multi-sugar assay for site-specific gastrointestinal permeability analysis: a randomized controlled crossover trial. Clin Nutr. 2013;32(2):245-51.

40. Dorshow RB, Hall-Moore C, Shaikh N, Talcott MR, Faubion WA, Rogers TE, et al. Measurement of gut permeability using fluorescent tracer agent technology. Sci Rep. 2017;7(1):10888.

41. Denno DM, VanBuskirk K, Nelson ZC, Musser CA, Hay Burgess DC, Tarr $\mathrm{PI}$. Use of the lactulose to mannitol ratio to evaluate childhood environmental enteric dysfunction: a systematic review. Clin Infect Dis. 2014;59(Suppl 4):S213-9.

42. Smith HE, Ryan KN, Stephenson KB, Westcott C, Thakwalakwa C, Maleta K, et al. Multiple micronutrient supplementation transiently ameliorates environmental enteropathy in Malawian children aged 12-35 months in a randomized controlled clinical trial. J Nutr. 2014;144(12):2059-65.

43. Weisz AJ, Manary MJ, Stephenson K, Agapova S, Manary FG, Thakwalakwa C, et al. Abnormal gut integrity is associated with reduced linear growth in rural Malawian children. J Pediatr Gastroenterol Nutr. 2012;55(6):747-50.

44. Blanton LV, Charbonneau MR, Salih T, Barratt MJ, Venkatesh S, Ilkaveya O, et al. Gut bacteria that prevent growth impairments transmitted by microbiota from malnourished children. Science. 2016;351(6275). doi: https://doi.org/10. 1126/science.aad3311. PubMed PMID: 26912898; PubMed Central PMCID: PMC4787260.

45. Subramanian S, Huq S, Yatsunenko T, Haque R, Mahfuz M, Alam MA, et al. Persistent gut microbiota immaturity in malnourished Bangladeshi children. Nature. 2014;510(7505):417-21.

46. Yatsunenko T, Rey FE, Manary MJ, Trehan I, Dominguez-Bello MG, Contreras $M$, et al. Human gut microbiome viewed across age and geography. Nature. 2012:486(7402):222-7.

47. Kau AL, Planer JD, Liu J, Rao S, Yatsunenko T, Trehan I, et al. Functional characterization of IgA-targeted bacterial taxa from undernourished Malawian children that produce diet-dependent enteropathy. Sci Transl Med. 2015;7(276):276ra24. 
48. Syed S, Duggan CP. Risk factors for malnutrition and environmental enteric dysfunction-you really are what you eat. J Pediatr. 2016;178:7-8.

49. Gevers D, Kugathasan S, Denson LA, Vazquez-Baeza Y, Van Treuren W, Ren $B$, et al. The treatment-naive microbiome in new-onset Crohn's disease. Cell Host Microbe. 2014;15(3):382-92.

50. Morgan XC, Tickle TL, Sokol H, Gevers D, Devaney KL, Ward DV, et al. Dysfunction of the intestinal microbiome in inflammatory bowel disease and treatment. Genome Biol. 2012;13(9):R79.

51. de Onis M, Onyango AW, Borghi E, Siyam A, Nishida C, Siekmann J. Development of a WHO growth reference for school-aged children and adolescents. Bull World Health Organ. 2007;85(9):660-7.

52. Ilumina. Infinium OmniExpressExome-8 Kit [Available from: https://www. illumina.com/products/by-type/microarray-kits/infinium-omni-expressexome.html. Accessed 8 Aug 2018.

53. Menendez-Corrada R, Nettleship E, Santiago-Delpin EA. HLA and tropical sprue. Lancet. 1986;2(8517):1183-5.

54. Goodrich JK, Waters JL, Poole AC, Sutter JL, Koren O, Blekhman R, et al. Human genetics shape the gut microbiome. Cell. 2014;159(4):789-99.

55. Palma GD, Capilla A, Nova E, Castillejo G, Varea V, Pozo T, et al. Influence of milk-feeding type and genetic risk of developing coeliac disease on intestinal microbiota of infants: the PROFICEL study. PLoS One. 2012;7(2):e30791.

56. Wacklin P, Tuimala J, Nikkila J, Sebastian T, Makivuokko H, Alakulppi N, et al. Faecal microbiota composition in adults is associated with the FUT2 gene determining the secretor status. PLoS One. 2014;9(4):e94863.

57. Schumann M, Siegmund B, Schulzke JD, Fromm M. Celiac disease: role of the epithelial barrier. Cell Mol Gastroenterol Hepatol. 2017;3(2):150-62.

58. Huttonhower Lab. Galaxy webserver The Huttenhower Lab - Department of Biostatistics, Harvard T.H. Chan School of Public Health [Available from: http://huttenhower.sph.harvard.edu/galaxy]. Accessed 28 Mar 2018.

59. Friedman JH. Stochastic gradient boosting. Comput Stat Data Anal. 2002; 38(4):367-78.

60. Benjamini $Y$, Hochberg Y. Controlling the false discovery rate: a practical and powerful approach to multiple testing. J R Stat Soc Ser B Methodol. 1995;57(1):289-300.

61. Trapnell C, Salzberg SL. How to map billions of short reads onto genomes. Nat Biotechnol. 2009;27(5):455.

62. Bray N PH, Melsted P, Pachter L. Near-optimal RNA-Seq quantification with kallisto. 2015. [Available from: https://liorpachter.wordpress.com/2015/05/10/ near-optimal-rna-seq-quantification-with-kallisto/]. Accessed 28 Mar 2018.

63. Roberts A, Pachter L. Streaming fragment assignment for real-time analysis of sequencing experiments. Nat Methods. 2013;10(1):71-3.

64. Chen J, Bardes EE, Aronow BJ, Jegga AG. ToppGene suite for gene list enrichment analysis and candidate gene prioritization. Nucleic Acids Res. 2009:37(Web Server issue):W305-11.

65. Kaimal V, Bardes EE, Tabar SC, Jegga AG, Aronow BJ. ToppCluster: a multiple gene list feature analyzer for comparative enrichment clustering and network-based dissection of biological systems. Nucleic Acids Res. 2010; 38(Web Server issue):W96-102.

66. Saito R, Smoot ME, Ono K, Ruscheinski J, Wang PL, Lotia S, et al. A travel guide to Cytoscape plugins. Nat Methods. 2012;9(11):1069-76.

67. Beam AL, Kohane IS. Big data and machine learning in health care. JAMA. 2018:319(13):1317-8

68. Ribeiro MT, Singh S, Guestrin C. Why should i trust you?: Explaining the predictions of any classifier. In: Proceedings of the 22nd ACM SIGKDD international conference on knowledge discovery and data mining: ACM; 2016. p. 1135-44.

69. LeCun Y, Bengio Y, Hinton G. Deep learning. Nature. 2015;521(7553):436-44.

70. Zeiler MD, Fergus R. Visualizing and understanding convolutional networks. In: European conference on computer vision. In: Springer; 2014. p. 818-33.

71. Zeiler MD, Krishnan D, Taylor GW, Fergus R. Deconvolutional networks. In: 2010 IEEE Computer Society Conference on Computer Vision and Pattern Recognition, CVPR, vol. 10; 2010. p. 7.

72. Selvaraju RR, Cogswell M, Das A, Vedantam R, Parikh D, Batra D. Grad-CAM: visual explanations from deep networks via gradient-based localization: arXiv preprint arXiv; 2016. p. 161002391.

73. Amadi B, Fagbemi AO, Kelly P, Mwiya M, Torrente F, Salvestrini $C$, et al. Reduced production of sulfated glycosaminoglycans occurs in Zambian children with kwashiorkor but not marasmus. Am J Clin Nutr. 2009;89(2): 592-600.
74. Joint Commission International. JCl Accredited Organizations [Available from: https://www.jointcommissioninternational.org/about-jci/jci-accreditedorganizations/]. Accessed 30 Apr 2018.

75. The Aga Khan University Hospital. World Class Quality Health Services [Available from: https://hospitals.aku.edu/pakistan/AboutUs/Pages/worldclass-quality-health-services.aspx.]. Accessed 30 Apr 2018.

76. Di Segni A, Braun T, BenShoshan M, Barhom SF, Saar EG, Cesarkas K, Squires JE, Keller N, Haberman Y. Guided protocol for fecal microbial characterization by $16 \mathrm{~S}$ rRNA-amplicon sequencing. J Vis Exp. 2018; 19(133):e56845

77. International Committee of Medical Journal Editors (ICMJE). Defining the Role of Authors and Contributers [Available from: http://www.icmje.org/ recommendations/browse/roles-and-responsibilities/defining-the-role-ofauthors-and-contributors.html]. Accessed 28 Mar 2018.
Ready to submit your research? Choose BMC and benefit from:

- fast, convenient online submission

- thorough peer review by experienced researchers in your field

- rapid publication on acceptance

- support for research data, including large and complex data types

- gold Open Access which fosters wider collaboration and increased citations

- maximum visibility for your research: over $100 \mathrm{M}$ website views per year

At $\mathrm{BMC}$, research is always in progress.

Learn more biomedcentral.com/submissions 